\title{
Factors Associated with Physical Activity among Medical Students of Jazan University: A Cross-Sectional Study
}

\author{
Husam Eldin Elsawi Khalafalla ${ }^{1}$, Mohamed Salih Mahfouz ${ }^{1}$, Muath Hassan Ibrahim Najmi ${ }^{2 \dagger}$, Sayyaf Abdullah \\ Mohammad Najmi ${ }^{2 \dagger}$, Qasem Ali Yahya Arishi ${ }^{2 \dagger}$, Albaraa Mohammad Jeadar Madkhali ${ }^{2 \dagger}$, Nasser Mansour \\ Mohammad Faris $^{2 \dagger} \&$ Ali Abdullah Ali Najmi ${ }^{2 \dagger}$ \\ ${ }^{1}$ Department of Community Medicine, Faculty of Medicine, Jazan University, Jazan, Kingdom of Saudi Arabia \\ ${ }^{2}$ Faculty of Medicine, Jazan University, Jazan, Kingdom of Saudi Arabia \\ Correspondence: Mohamed Salih Mahfouz, Faculty of Medicine, Jazan University, Jazan, Kingdom of Saudi \\ Arabia. E-mail: mm.mahfouz@gmail.com
}

$\dagger$ These authors contributed equally to this work.

Received: February 5, 2017 Accepted: March 2, 2017 Online Published: March 20, 2017

doi:10.5539/gjhs.v9n4p266 URL: https://doi.org/10.5539/gjhs.v9n4p266

\begin{abstract}
Background: Physical activity is one of the most important factors that affect human health; it reduces the chances of hypertension, coronary heart disease, stroke, diabetes, breast and colon cancer, and depression.
\end{abstract}

Objectives: The objectives of this study were to measure prevalence of physical activity and to determine the factors affecting the level of physical activity among medical student in Jazan University.

Methods: A cross-sectional study was conducted among the students of medical colleges of Jazan University. A random sample of 419 was determined using most recent physical activity prevalence. A validated self-administered questionnaire was used for data collection.

Results: There is a high prevalence of inactivity among study participants (88.1\%). Females $(91.7 \%)$ were more significantly ( $p$ value $=0.013$ ) inactive than males $(83.8 \%)$. The most influential barrier perceived by participants is (heavy) academic work as well as lack of places for physical activity; the latter factor being more effective in hindering female students' physical activity.

Conclusion: Results revealed that the inactivity rate was very high among medical students. The results of this study call for a well-planned intervention at the university level for improving the level of physical activity among university students.

Keywords: physical activity, inactivity rate, Jazan University, medical students

\section{Introduction}

Physical inactivity is an important modifiable risk factor for many non-communicable diseases (NCDs). Globally, physical inactivity (PIA) contributes considerably to ischaemic heart disease, diabetes mellitus, and breast, colon, and rectal cancers (WHO, 2002).

According to Lee et al. (2012), PIA were responsible for about $6 \%$ of coronary heart disease burden $(7.8 \%$ in the Eastern Mediterranean Region), as well as $7 \%$ of type 2 diabetes, and $10 \%$ of both breast and colon cancers. PIA was held responsible for $9 \%$ of premature mortality of all deaths worldwide of the year 2008. Moreover, Haskell et al. (2007) found a dose-response relationship between physical activity and health effects.

In the few last decades, the Kingdom of Saudi Arabia has witnessed changes in the standards of living and level of urbanization that has caused a deleterious effect on physical activity. Studies about the prevalence of physical inactivity in the Kingdom of Saudi Arabia reported a range of 43-99.5\% of inactive Saudis. This broad range is perhaps due to differences in assessment methods, regions, and age groups involved. (Al-Hazzaa, 2004)

Al-Hazzaa, (2004) found that physical inactivity has the greatest prevalence compared to other risk factors of CHD, hypertension, and hypercholesterolemia. Both social and physical environments have great influence on physical activity. Regarding social environment, family and friends can affect the attitude of people toward and practicing 
physical activity. The physical environment including time, outdoor, weather, season, activity program and weekend has significant effect practice physical activity (Rees et al., 2006,).

Physical activity is not significantly associated with some variables like type of work or education. Al-Nuaim et al. (2012) found that young males who are overweight or obese are less active than their counterparts of "regular" weight. There were more inactive females $(98.1 \%)$ than males $(93.9 \%)$, the difference often being significant (Al-Nozha et al., 2007). Inactivity prevalence increased with the increase in age, especially in men. Married individuals are more physically inactive than singles.

Many reasons were cited for being physically inactive by participants in different studies. Saudi males cite the absence of suitable place, health problems, and fear of embarrassment as reasons for being inactive (Hazzaa $\mathrm{M}$ Al-Hazzaa, 2000), time constraint (Al-Otaibi, 2013; Hazzaa M Al-Hazzaa, 2000; Al-Refaee \& Al-Hazzaa, 2001). Some individuals cite lack of motivation as an obstacle (Al-Otaibi, 2013). However, some find motivation in weight loss and maintaining their health (Al-Refaee \& Al-Hazzaa, 2001).

The southern region of Saudi Arabia had the lowest level of physical inactivity of $94 \%$, while the central region had the highest level of $97.3 \%$ (Al-Nozha et al., 2007).

The main objective of this study is to estimate the prevalence physical activity among undergraduate medical students of Jazan University and to assess factors associated with physical inactivity among this important group.

\section{Methods}

\subsection{Study Place, Design, and Participants}

Jazan University is the leading higher educational institution located in Jazan region. Jazan region is situated in Southwest Saudi Arabia. It is one of the 13 provinces of the Kingdom of Saudi Arabia. This is an observational, cross-sectional survey that targeted medical students of Jazan University registered for the academic year 2013/2014. The target colleges were Applied Medical Sciences, Pharmacy, Dentistry, and Medicine.

\subsection{Sampling Procedures}

We proposed a sample size of 440 participants for this study. The sample size was determined using the statistical equation for a single cross-sectional study denoted by the follwing, $n=\left[\left(\mathrm{z}^{2} * \mathrm{p} *(1-\mathrm{p})\right] / \mathrm{d}^{2}\right.$. Parameters used for sample size calculation was: $\mathrm{p}=$ prevalence of physical inactivity $=50 \%, \mathrm{Z}=95 \%$ confidence interval, and $\mathrm{d}=$ error $\leq 5 \%$. Probability proportional to size sampling (PPS) was used to determine the number of students in each of the selected college.

\subsection{Data Collection}

An Arabic structured questionnaire was used for data collection purposes. The instrument used for this study was adapted form the Questionnaire developed by (Hazza Al-Hazza, 2000), which was used to measure prevalence of physical activity in youth (15-25) years old. The validity and reliability of this questionnaire has been assessed. The final version of the questionnaire involved approximately 50 questions divided into four categories. The first section involved background characteristic questions, the second group were questions on prevalence of physical activity. The third group included questions on the pattern of physical activities. The final section contained questions on factors that affect the practice of physical activity.

\subsection{Data Processing and Statistical Analysis}

The questionnaire papers were verified and entered by study team and then merged into one device. The data were analyzed using SPSS ver. 20 (SPSS, Chicago, IL, USA). Descriptive (frequency and percentage) and inferential statistics (chi-square test) were used to interpret the data. $p$ value less than $5 \%$ was used as a cutoff point to indicate statistical significance.

\subsection{Ethical Consideration}

This study was conducted in accordance with the ethical standards of the Kingdom of Saudi Arabia. All participants read, understood, and signed a written consent form. Participants were told that they had the right to withdraw from the study at any time and their information would be kept anonymous.

\section{Results}

Table 1 provides background characteristics of the study participants including age, college name, marital status, and residency. The table showed that most students were $19-21$ years old $(55.6 \%)$, single $(92.2 \%)$, and live in urban areas $(64.0 \%)$ compared to rural areas (36.6\%). Almost half of the study participants were from Applied Medical Sciences $50.4 \%$. 
Table 2 compares physical activity between males and female students in each college. The overall prevalence of physical activity in males and females students who meet the recommendation level of WHO (at least $150 \mathrm{~min}$. per week) was $16.2 \%$ and $8.3 \%$ with significant differences between males and females ( $p$ value $<0.05$ ). The highest prevalence of physical activity among male students was reported in Applied Medical Sciences (20.7\%) [95\% C.I. 13.5\%-30.4\%], while among female's students in Dentistry (10.7\%) [95\% C.I. 3.9\%-27.4\%].

Table 3 demonstrates the factors that could affect the physical activity level distributed by gender. Initially a 5-point Likert scale was used. In the table, the categories "strongly agree" and "agree" were merged and displayed as "Agree." Likewise, "strongly disagree" and "disagree" were merged as "Disagree". The significance of gender distribution was also shown for the factors and a $\boldsymbol{p}$. value less than 0.05 was considered as significant. The factors that are considered by participants of both sexes to be of more influence are "No available places for exercise," and being busy, accounting to more than two-thirds of the participants in each. There are a number of interesting gender differences in all factors. Moreover, all these gender differences were significant ( $\boldsymbol{p}$ value less than 0.05).

Table 1. Some selected background characteristics

\begin{tabular}{llll}
\hline \multirow{2}{*}{ Characteristics } & \multicolumn{2}{c}{ Gender } & Total \\
\cline { 2 - 3 } & Male (\%) & Female (\%) & \\
\hline Age & $88(48.4)$ & $130(61.9)$ & $218(55.6)$ \\
$22-24$ & $92(50.5)$ & $79(37.6)$ & $171(43.6)$ \\
$25+$ & $2(1.1)$ & $1(0.5)$ & $3(0.8)$ \\
\hline College & & & $88(21.0)$ \\
Medicine & $40(20.9)$ & $48(21.1)$ & $60(14.3)$ \\
Dentistry & $32(16.8)$ & $28(12.3)$ & $60(14.3)$ \\
Pharmacy & $32(16.8)$ & $28(12.3)$ & $211(50.4)$ \\
Applied Medical Sci. & $87(45.5)$ & $124(54.4)$ & $380(92.2)$ \\
\hline Marital Status & & & $29(7.0)$ \\
Single & $176(95.7)$ & $204(89.5)$ & $1(0.2)$ \\
Married & $7(3.8)$ & $22(9.6)$ & $2(0.9)$ \\
Divorced & $1(0.5)$ & $0(0.0)$ & $148(36.0)$ \\
Widowed & $0(0.0)$ & $2(0.5)$ & $263(64.0)$ \\
\hline Residence & & $58(25.4)$ & \\
Rural & $90(49.2)$ & $170(74.6)$ & \\
Urban & $93(50.8)$ & & \\
\hline
\end{tabular}


Table 2. Prevalence of physical activity according gender and college

\begin{tabular}{|c|c|c|c|c|}
\hline \multirow[b]{2}{*}{ College } & \multicolumn{2}{|l|}{ Gender } & \multirow{2}{*}{$\begin{array}{l}\text { Total } \\
\% \text { (95\% C.I) }\end{array}$} & \multirow[b]{2}{*}{$p$ value } \\
\hline & $\begin{array}{l}\text { Male } \\
\%(95 \% \text { C.I })\end{array}$ & $\begin{array}{l}\text { Female } \\
\%(95 \% \text { C.I) }\end{array}$ & & \\
\hline Medicine $(n=88)$ & $15(7.2-29.2)$ & $4.2(1.3-14.0)$ & $9.1(4.27-16.9)$ & 0.078 \\
\hline Dentistry $(n=60)$ & $12.5(5.1-28.2)$ & $10.7(3.9-27.4)$ & $11(5.83-22.8)$ & 0.830 \\
\hline Pharmacy $(n=60)$ & $9.4(3.4-24.3)$ & $3.6(0.8-17.8)$ & $6.7(2.7-15.9)$ & 0.369 \\
\hline Applied Medical Sciences $(n=211)$ & $20.7(13.5-30.4)$ & $10.5(6.3-17.1)$ & $14.7(10.6-20.1)$ & 0.013 \\
\hline Overall Prevalence $(n=419)$ & $16.2(11.7-22.1)$ & $8.3(5.4-12.7)$ & $11.9(9.2-15-3)$ & 0.013 \\
\hline
\end{tabular}

Table 3. Factors Affecting physical activity in both males and females

\begin{tabular}{|c|c|c|c|c|c|c|c|}
\hline \multirow{2}{*}{ Factor } & \multicolumn{3}{|l|}{ Male } & \multicolumn{3}{|l|}{ Female } & \multirow{2}{*}{$p$ value } \\
\hline & Agree & Neutral & Disagree & Agree & Neutral & Disagree & \\
\hline $\begin{array}{l}\text { No Available Places } \\
\text { for Exercise }\end{array}$ & $140(73.3)$ & $14(7.3)$ & $37(19.3)$ & $203(89)$ & $8(3.5)$ & $17(7.4)$ & .000 \\
\hline $\begin{array}{l}\text { Busy } \\
\text { (Studying/Working) }\end{array}$ & $159(84.2)$ & $22(11.6)$ & $8(4.2)$ & $214(94.3)$ & $9(4)$ & $4(1.7)$ & .003 \\
\hline $\begin{array}{l}\text { Having a health } \\
\text { condition/Disease }\end{array}$ & $38(20)$ & $36(18.9)$ & $116(61.1)$ & $58(25.8)$ & $42(18.7)$ & $125(55.6)$ & .000 \\
\hline Bad weather & $71(37.7)$ & $55(29.3)$ & $62(33)$ & 147 (64.4) & $34(14.9)$ & $47(20.6)$ & .000 \\
\hline Fear of Injuries & $47(24.6)$ & $56(29.3)$ & $88(46.1)$ & $45(19.8)$ & $50(21.9)$ & $133(58.3)$ & .085 \\
\hline Exhaustion & $84(44)$ & $49(25.7)$ & $58(30.3)$ & $118(52.2)$ & $49(21.7)$ & $59(26.1)$ & .073 \\
\hline $\begin{array}{l}\text { Use of the Internet } \\
\text { and Social Media }\end{array}$ & $96(50.5)$ & $43(22.6)$ & $51(26.9)$ & $151(66.8)$ & $27(11.9)$ & $48(21.2)$ & .001 \\
\hline Social disapproval & $35(18.4)$ & $33(17.4)$ & $122(64.2)$ & $64(28.1)$ & $35(15.4)$ & $129(56.6)$ & .008 \\
\hline
\end{tabular}

\section{Discussion}

Regular moderate physical activity has significant benefits for human health while less active persons have a greater risk of developing many undesirable health conditions. It is agreed that physical activity is a global concern and in the kingdom of Saudi Arabia, it is of particular importance as physical inactivity is found to be the most prevalent risk factor. The results of this study shed the light on interesting findings about the study population of Jazan University at the South of the Kingdom of Saudi Arabia.

This study determined the prevalence of physical inactivity and the factors perceived to be influencing it. The prevalence obtained in this study of $11.9(9.2-15.3)$ is very low when compared to levels reported globally and in the Gulf Region, and even lower than what is reported by (Hazzaa M Al-Hazzaa, 2000), (prevalence of 19-22\% among young adults). International studies show greater differences; Varela-Mato et al.(2012) found 27.4\% of Spanish university students to be active, which is still lower than $41 \%$ active Australian students (Rissel et al., 2012).

This study showed that the prevalence of physical inactivity in females was $91.7 \%$, which was significantly higher than in males (83.8\%). This finding is similar to other studies: local (Al-Nuaim et al., 2012; Al-Otaibi, 2013), international (Varela-Mato et al., 2012), and reviews (Al-Nozha et al., 2007,H. M. Al-Hazzaa, 2004). The slight urban rural difference in this study contradicts the findings of Al-Nozha et al. (2007), who found no significant differences.

Al Nozaha (2007) mentioned in his study that the category of married physically inactive participants were around $96.0 \%$, higher than the single ones (93.5\%); while in this study, the prevalence among single participants was $88.5 \%$ almost similar to married study participants $(86.6 \%)$. In this study, work or study is the main factor $(89 \%)$ affecting the level of physical activity, while in the Al-Refaee \& Al-Hazzaa study, lack of time seems to be the main reason 
that contribute to inactivity, which is the third factor in this study (Al-Refaee \& Al-Hazzaa, 2001).

In a study conducted by Al-Hazza, the most important reasons for being physically inactive among Saudi males was time constraint (47.3\%), lack of places (23.5\%), medical problems that prevent among individuals $(9.9 \%)$, and fear of embarrassment $(9.2 \%)$, while the most important reasons for being physically inactive in this study were: "academic study" (63.9\%), "no available place for exercise" (56.3\%), and "time constraint" (47.1\%). Time constraint as a barrier scored a very similar result (47.3\%). Hazzaa M Al-Hazzaa (2000) also cited lack of places $(23.5 \%)$, medical problems that prevent individuals $(9.9 \%)$, and fear of embarrassment $(9.2 \%)$ as the most important barriers. Climate might have a great influence on physical activity in some countries (Booth, 2000) and "bad weather" is cited by participants as a deterrent to exercise with a significant gender difference as females are more affected.

Finally, some limitations in the present study should be taken into consideration. Firstly, the study was based on a cross-sectional study design, so the study results should be understood in this context. Secondly, we included only medical colleges of Jazan University, which will affect the level of generalization of study outcomes.

\section{Conclusions and Recommendations}

In conclusion, the inactivity prevalence was very high among study participants and significantly higher among females than males. The most influential barrier perceived by participants is (heavy) academic work as well as lack of places for physical activity; the latter factor being more effective in hindering female students' physical activity. The results of this study calls for a well-planned intervention at the university level that can target the perceived barriers. The most modifiable barrier might be the lack of places and facilities, which can be availed by university administration within campuses.

\section{Authors' Contributions}

The authors contributed equally.

\section{Acknowledgements}

We would like to thank all staff of the department of Family and Community Medicine, Jazan University for their help and support. Also, we appreciate the contributions of all students who sacrificed with their valuable time and answered the study questionnaire.

\section{Competing Interests Statement}

The authors declare that there is no conflict of interests regarding the publication of this paper.

\section{References}

Al-Hazzaa, H. M. (2000). Patterns of Physical Activity Among Saudi Children, Adolescents, and Adults With Special Reference To Health. In A. Musaiger \& S. Miladi (Eds.), Nutrition \& Physical Activity in the Arab Countries of the Near East, (pp. 109-127). Manama: BCSR.

Al-Hazzaa, H. M. (2004). Prevalence of physical inactivity in Saudi Arabia: A brief review. Eastern Mediterranean Health Journal, 10(4-5), pp. 663-670.

Al-Nozha, M. M., Al-Hazzaa, H. M., Arafah, M. R., Al-Khadra, A., Al-Mazrou, Y. Y., Al-Maatouq, M. A., ... Al-Shahid, M. S. (2007). Prevalence of physical activity and inactivity among Saudis aged 30-70 years: A population-based cross-sectional study. Saudi Medical Journal, 28(4), 559-568. http://doi.org/20060992'

Al-Nuaim, A. A., Al-Nakeeb, Y., Lyons, M., Al-Hazzaa, H. M., Nevill, A., Collins, P., \& Duncan, M. J. (2012). The prevalence of physical activity and sedentary behaviours relative to obesity among adolescents from Al-ahsa, Saudi Arabia: Rural versus urban variations. Journal of Nutrition and Metabolism, 2012. https://doi.org/10.1155/2012/417589

Al-Otaibi, H. H. (2013). Measuring stages of change, perceived barriers and self efficacy for physical activity in Saudi Arabia. Asian Pacific Journal of Cancer Prevention, 14(2), 1009-1016. https://doi.org/10.7314/APJCP.2013.14.2.1009

Al-Refaee, S. A., \& Al-Hazzaa, H. M. (2001). Physical activity profile of adult males in Riyadh City. Saudi Medical Journal, 22(9), 784-789.

Booth, M. (2000). Assessment of physical activity an international perspective. Research Quarterly for Exercise and Sport, 71(2), s114-s120. https://doi.org/10.1080/02701367.2000.11082794

Haskell, W. L., Lee, I. M., Pate, R. R., Powell, K. E., Blair, S. N., Franklin, B. A., .. Bauman, A. (2007). Physical activity and public health: Updated recommendation for adults from the American College of Sports 
Medicine and the American Heart Association. Medicine and Science in Sports and Exercise, 39(8), 1423-1434. https://doi.org/10.1249/mss.0b013e3180616b27

Lee, I.-M., Shiroma, E. J., Lobelo, F., Puska, P., Blair, S. N., \& Katzmarzyk, P. T. (2012). Impact of Physical Inactivity on the World's Major Non-Communicable Diseases. Lancet, 380(9838), $219-229$. http://doi.org/10.1016/S0140-6736(12)61031-9.Impact

Rees, R., Kavanagh, J., Harden, A., Shepherd, J., Brunton, G., Oliver, S., \& Oakley, A. (2006). Young people and physical activity: A systematic review matching their views to effective interventions. Health Education Research, 21(6), 806-825. hhttps://doi.org/10.1093/her/cyl120

Rissel, C., Mulley, C., \& Ding, D. (2012). Travel Mode and Physical Activity at Sydney University. Int. J. Environ. Res. Int. J. Environ. Res. Public Health, 103390(10), 3563-3577. https://doi.org/10.3390/ijerph10083563

Varela-Mato, V., Cancela, J. M., Ayan, C., Martín, V., \& Molina, A. (2012). Lifestyle and Health among Spanish University Students: Differences by Gender and Academic Discipline. Int. J. Environ. Res. Public Health, 9(9), 2728-2741. https://doi.org/10.3390/ijerph9082728

\section{Copyrights}

Copyright for this article is retained by the author(s), with first publication rights granted to the journal.

This is an open-access article distributed under the terms and conditions of the Creative Commons Attribution license (http://creativecommons.org/licenses/by/4.0/). 